\title{
Right-to-left shunt with hypoxemia in pulmonary hypertension
} Jean-Frédéric Vodoz ${ }^{\dagger 1}$, Vincent Cottin* ${ }^{* 1,2,5}$, Jean-Charles Glérant ${ }^{3}$, Geneviève Derumeaux ${ }^{2,4}$, Chahéra Khouatra ${ }^{1}$, Anne-Sophie Blanchet ${ }^{1,2}$, Bénédicte Mastroïanni ${ }^{1}$, Jean-Yves Bayle ${ }^{3}$, Jean-François Mornex ${ }^{1,2,5}$ and JeanFrançois Cordier ${ }^{1,2,5}$

\begin{abstract}
Address: ${ }^{1}$ Service de pneumologie et centre de référence des maladies orphelines pulmonaires, Hôpital Louis Pradel, Hospices Civils de Lyon, Lyon France, ${ }^{2}$ Université Lyon I, Université de Lyon, Lyon, France, ${ }^{3}$ Laboratoire d'exploration fonctionnelle respiratoire, Hôpital Louis Pradel, Hospices Civils de Lyon, Lyon, France, ${ }^{4}$ Laboratoire d'échocardiographie, Hôpital Louis Pradel, Hospices Civils de Lyon, Lyon, France and ${ }^{5}$ UMR754 RPC, Ecole Nationale Vétérinaire de Lyon, Ecole pratique des hautes études, IFR128, INRA, Lyon, France

Email: Jean-Frédéric Vodoz - jean-frederic.vodoz@chuv.ch; Vincent Cottin* - vincent.cottin@chu-lyon.fr; Jean-Charles Glérant - jeancharles.glerant@chu-lyon.fr; Geneviève Derumeaux - genevieve.derumeaux@chu-lyon.fr; Chahéra Khouatra - chahera.khouatra@chu-lyon.fr; Anne-Sophie Blanchet - asblanchetlegens@ch-stjoseph-stluc-lyon.fr; Bénédicte Mastroïanni - benedicte.mastroianni@chu-lyon.fr; JeanYves Bayle - jy-bayle@orange.fr; Jean-François Mornex - mornex@univ-lyon1.fr; Jean-François Cordier - jean-francois.cordier@chu-lyon.fr

* Corresponding author †Equal contributors
\end{abstract}

Published: 3I March 2009

BMC Cardiovascular Disorders 2009, 9:15 doi:10.1186/1471-2261-9-15

This article is available from: http://www.biomedcentral.com/I47I-226I/9//5

(C) 2009 Vodoz et al; licensee BioMed Central Ltd.

This is an Open Access article distributed under the terms of the Creative Commons Attribution License (http://creativecommons.org/licenses/by/2.0), which permits unrestricted use, distribution, and reproduction in any medium, provided the original work is properly cited.
Received: 18 November 2008

Accepted: 31 March 2009

\begin{abstract}
Background: Hypoxemia is common in pulmonary hypertension (PH) and may be partly related to ventilation/perfusion mismatch, low diffusion capacity, low cardiac output, and/or right-to-left (RL) shunting.

Methods: To determine whether true RL shunting causing hypoxemia is caused by intracardiac shunting, as classically considered, a retrospective single center study was conducted in consecutive patients with precapillary $\mathrm{PH}$, with hypoxemia at rest $\left(\mathrm{PaO}_{2}<10 \mathrm{kPa}\right)$, shunt fraction $(\mathrm{Qs} / \mathrm{Qt})$ greater than $5 \%$, elevated alveolar-arterial difference of $\mathrm{PO}_{2}\left(\mathrm{AaPO}_{2}\right)$, and with transthoracic contrast echocardiography performed within 3 months.
\end{abstract}

Results: Among 263 patients with precapillary $\mathrm{PH}, 34$ patients were included: pulmonary arterial hypertension, $21 \%$; $\mathrm{PH}$ associated with lung disease, 47\% (chronic obstructive pulmonary disease, $23 \%$; interstitial lung disease, $9 \%$; other, I5\%); chronic thromboembolic $\mathrm{PH}, 26 \%$; miscellaneous causes, $6 \%$. Mean pulmonary artery pressure, cardiac index, and pulmonary vascular resistance were $45.8 \pm 10.8 \mathrm{mmHg}, 2.2 \pm 0.6 \mathrm{~L} / \mathrm{min} / \mathrm{m}^{2}$, and $469 \pm 275$ dyn.s.cm-5, respectively. $\mathrm{PaO}_{2}$ in room air was $6.8 \pm 1.3 \mathrm{kPa}$. Qs/Qt was $10.2 \pm 4.2 \%$. AaPO under $100 \%$ oxygen was $32.5 \pm 12.4 \mathrm{kPa}$. Positive contrast was present at transthoracic contrast echocardiography in $6 / 34$ (I8\%) of patients, including only 4/34 (I2\%) with intracardiac RL shunting. Qs/Qt did not correlate with hemodynamic parameters. Patients' characteristics did not differ according to the result of contrast echocardiography.

Conclusion: When present in patients with precapillary $\mathrm{PH}, \mathrm{RL}$ shunting is usually not related to reopening of patent foramen ovale, whatever the etiology of $\mathrm{PH}$. 


\section{Background}

Pulmonary hypertension $(\mathrm{PH})$ is characterized by increased pulmonary artery pressure, ultimately leading to right heart failure and death. PH encompasses various etiologic groups, including pulmonary arterial hypertension (PAH) - group 1, PH related to left heart disease group 2, PH associated with lung diseases and/or hypoxemia - group 3, PH due to chronic thrombotic and/or embolic disease - group 4, and miscellaneous disorders, including sarcoidosis and Langerhans cell histiocytosis group $5[1]$.

PAH per se affects small pulmonary arteries, with vascular remodelling leading to progressive increase in pulmonary vascular resistance (PVR) [2]. It may be idiopathic, familial, or associated with a variety of conditions merged under the common denomination of PAH due to similarities in histopathological features, natural history, and treatment [1]. Precapillary PH is defined by PH with pulmonary artery wedge pressure (PAWP) no greater than 15 mmHg and PVR greater than 240 dyn.s. $\mathrm{cm}^{-5}$ [1]. In addition to PAH, precapillary $\mathrm{PH}$ may be encountered as a result of various disorders (etiologic groups 3, 4, and 5), and may also be characterized by remodelling of the small pulmonary arteries although less data are available than in $\mathrm{PAH}$.

Mild to moderate hypoxemia is common in precapillary $\mathrm{PH}$, and most often coexists with respiratory alkalosis. Hence, the mean $\mathrm{PaO}_{2}$ was $9.5 \pm 2 \mathrm{kPa}$ in the National Institutes of Health PAH registry [3] and $9.2 \pm 1.9 \mathrm{kPa}$ in a more recent study [4]. However, hypoxemia in PH may sometimes be severe and contribute to exercise intolerance. Desaturation of $10 \%$ or more during 6-minute walk test is associated with a relative mortality risk of 2.9 in $\mathrm{PAH}$ [5]. Desaturation may occur overnight in as many as $60 \%$ of patients with PAH [6].

Hypoxemia in precapillary PH may possibly be related to ventilation/perfusion mismatch $[7,8]$, low diffusion capacity, low mixed venous $\mathrm{PO}_{2}$ due to decreased cardiac output [9], and/or true right-to-left (RL) shunting, which is classically considered to arise from the reopening of patent foramen ovale $[3,10,11]$. In clinical practice guidelines for the diagnostic process of $\mathrm{PAH}$, transthoracic contrast echocardiography is recommended to look for evidence of intracardiac shunting [11]. However, little evidence is available in the medical literature regarding this issue.

Here, we studied consecutive patients with precapillary $\mathrm{PH}$, hypoxemia, and true RL shunting, in whom transthoracic contrast echocardiography was available, to determine whether true RL shunting causing hypoxemia is due to intracardiac shunting and especially patent foramen ovale.

\section{Methods}

A computer-aided search was conducted to identify all adult patients evaluated for precapillary $\mathrm{PH}$ at our institution between January 2001 and March 2007. Patients with RL shunting and available transthoracic contrast echocardiography were then selected using the computerized database of the department of pulmonary function tests and manual review of the medical records, respectively. The study was approved by the Institutional Review Board of the Société de Pneumologie de Langue Française. Informed consent was obtained.

Inclusion criteria for this study included: (1) precapillary $\mathrm{PH}$ as defined by mean pulmonary arterial pressure (mPAP) greater than $25 \mathrm{mmHg}$ at rest, with PAWP 15 mmHg or less, and PVR greater than 240 dyn.s.cm ${ }^{-5}$ at right heart catheterization; [11] (2) hypoxemia defined by $\mathrm{PaO}_{2}$ at rest less than $10 \mathrm{kPa}$; (3) RL shunting as defined by shunt fraction (Qs/Qt) greater than 5\%; (4) elevated $\mathrm{AaPO}_{2}$ under $100 \% \mathrm{O}_{2}$; and (5) transthoracic contrast echocardiography performed within 3 months.

Causes of PH were classified according to the 2003 Venice classification [1]. Patients with PH associated with congenital systemic-to-pulmonary shunts and those with a known comorbidity potentially associated with a RL shunt (e.g. hemorrhagic hereditary telangiectasia) were excluded.

Shunt ratio (Qs/Qt) was calculated with the formula (Cc $\mathrm{Ca}) /(\mathrm{Cc}-\mathrm{Cv})$ while breathing $100 \%$ oxygen [12]. Qs and Qt corresponded to the shunt output and to total blood flow through the lungs, respectively. $\mathrm{Ca}$ and $\mathrm{Cv}$ corresponded to the oxygen contents of arterial and venous blood, respectively. Cc was the oxygen contents of endcapillary blood (with capillary $\mathrm{PO}_{2}$ estimated as similar to alveolar $\mathrm{PO}_{2}$ ). In 10 patients in whom Cc was not available, Qs/Qt was estimated with the formula $\left(\mathrm{PAO}_{2}-\mathrm{PaO}_{2}\right.$ $\mathrm{mmHg}) /\left(\mathrm{PAO}_{2}-\mathrm{PaO}_{2} \mathrm{mmHg}+1670\right)$ under $100 \%$ oxygen [13]; estimation of $\mathrm{Qs} / \mathrm{Qt}$ was validated in the remaining 24 patients by comparison of Qs/Qt and estimated Qs/Qt using Bland-Altman method; the bias value was $-0.1 \% \pm 0.67$ (95\% confidence interval, $-1.46-1.16$ ).

Pulmonary function tests were performed according to the European Respiratory Society guidelines [14]. $\mathrm{AaPO}_{2}$ while breathing $100 \% \mathrm{O}_{2}$ was performed as described elsewhere [15]; briefly, $\mathrm{PaO}_{2}$ was measured while the patient had been breathing $100 \% \mathrm{O}_{2}$ for at least $10-15$ minutes, with a deep inspiration every minute and immediately before drawing blood. Blood gas measurement was performed immediately after blood drawing, in the same room, with particular attention to eliminate air bubbles in the syringes. The actual $\mathrm{P}_{\mathrm{I}} \mathrm{O}_{2}$ was measured to estimate $\mathrm{PAO}_{2}$, with $\mathrm{PAO}_{2}(\mathrm{kPa})=\mathrm{P}_{\mathrm{I}} \mathrm{O}_{2}-6.27-\left(\mathrm{PaCO}_{2} / 0.8\right)$, 
and $\mathrm{AaPO}_{2}=\mathrm{PAO}_{2}-\mathrm{PaO}_{2}$. Thresholds of $\mathrm{AaPO}_{2}(18.6 \mathrm{kPa}$ in supine position, and $24.5 \mathrm{kPa}$ in upright position) determined previously [15] have excellent specificity (98\%), positive predictive value (97\%), and positive likelihood ratio (21.8) for the diagnosis of RL shunting higher than physiological shunting (5\%).

Transthoracic contrast echocardiography (second harmonic imaging) was performed by injecting $10 \mathrm{ml}$ of agitated isotonic saline solution mixed with $0.5 \mathrm{ml}$ of room air into a humeral vein while simultaneously imaging the atria from the apical 4-chamber view with 2-D echocardiography for at least 12 cardiac cycles. Contrast echocardiography was performed both in supine and sitting position, with Valsalva manoeuvre when negative. Intracardiac RL shunt was defined by appearance of any contrast in the left atrium within 4 cardiac cycles, and intrapulmonary shunt by a delayed contrast appearance (more than 5 cardiac cycles).

Right heart catheterization was performed using standard procedures. A Swan-Ganz catheter was introduced into an antecubital or femoral vein and guided under radioscopic control into the pulmonary artery, until wedged position was reached. Pressures were measured according to standard procedures. Cardiac output was calculated by cold thermodilution (Edwards Lifesciences, Germany) from at least 5 measurements. Arterial blood was drawn from the Swan-Ganz catheter for the measurement of $\mathrm{PO}_{2}$ and the mixed venous oxygen saturation $\left(\mathrm{SvO}_{2}\right)$ (ABL820 Radiometer, Copenhagen). Acute vasodilatator response was defined by a reduction of $\mathrm{mPAP} \geq 10 \mathrm{mmHg}$ to reach an absolute value of $\mathrm{mPAP} \leq 40 \mathrm{mmHg}$, with an increased or unchanged cardiac output $[16,17]$.

Microsoft Excel 2003 and SPSS 12.1 were used for data analysis. Data were presented as mean \pm SD (range). Comparisons between groups were performed using the MannWhitney U test, Kruskal Wallis test, and linear regression analysis, when appropriate. Comparison of distribution of causes were performed using Chi-square analysis. Twotailed $p$ values $<0.05$ were considered statistically significant.

\section{Results \\ Study population}

Among 310 patients evaluated in our department for $\mathrm{PH}$ during the study period, 263 had precapillary $\mathrm{PH}$ at right heart catheterization; 34 of them fulfilling the other inclusion criteria were included (figure 1). The clinical characteristics of the patients are shown in table 1 . The mean age was $64 \pm 15$ years, and the male/female sex ratio was 1.3.

Etiologic groups of PH were as follows (table 2): $21 \%$ with $\mathrm{PAH}$ (etiologic group 1); $47 \%$ with $\mathrm{PH}$ associated with
Table I: Clinical and functional characteristics at the time of diagnosis of pulmonary hypertension.

\begin{tabular}{lc}
\hline Clinical and functional parameters & Mean \pm SD (range) \\
\hline Age, yr & $64.0 \pm 15(25-82)$ \\
Sex (M/F) & $19 / 15$ \\
Ex- or active smokers, \% & 50 \\
Dyspnea NYHA class III-IV, \% & 76 \\
6-min-walk distance, m & $271 \pm 116(32-465)$ \\
TLC, \% predicted & $89 \pm 16(51-121)$ \\
FEV,$\%$ predicted & $76 \pm 20(33-117)$ \\
FEV /FVC, \% & $65 \pm 11(36-88)$ \\
DLco, \% predicted & $49 \pm 30(12-113)$ \\
DLco/VA, \% predicted & $51 \pm 28(11-113)$ \\
PaO2, kPa & $6.8 \pm 1.3(4.5-10.0)$ \\
\hline
\end{tabular}

FEVI, forced expiratory volume in one second; TLC, total lung capacity; DLco, single-breath diffusing capacity of the lung for carbon monoxide; VA, alveolar volume; NYHA, New York Heart Association.

Data expressed are mean \pm SD (range) for quantitative values.

chronic parenchymal lung disease (group 3); 26\% with $\mathrm{PH}$ related to thromboembolic obstruction of distal pulmonary arteries but not amenable to surgery (group 4); $6 \%$ with other causes (group 5). Distribution of etiologic groups did not differ from the overall population of 263 patients evaluated for precapillary $\mathrm{PH}$ in our department.

Most patients had severe dyspnea, as the median New York Heart Association (NYHA) functional class was III, and $76 \%$ of patients had functional class III-IV. Accordingly, the mean distance at 6-minute walk test was $271 \pm$

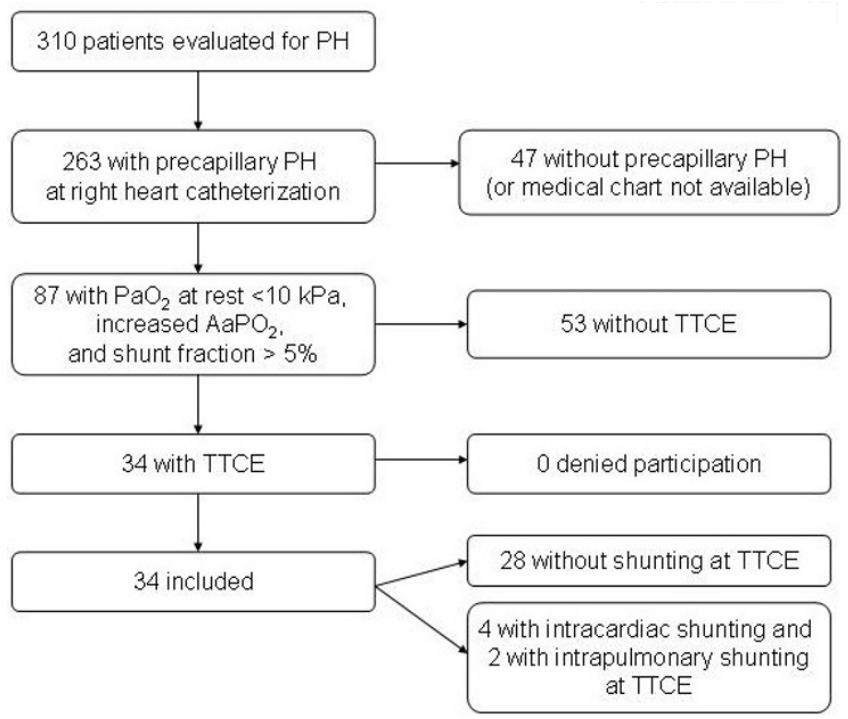

Figure I

Flowchart summarizing the selection and inclusion process. $\mathrm{PH}$, pulmonary hypertension; TTCE, transthoracic contrast echocardiography. 
Table 2: Etiologic groups of pulmonary hypertension [I].

\begin{tabular}{lc}
\hline Etiologic group & \\
\hline Pulmonary arterial hypertension (group I) & $7(21 \%)$ \\
Idiopathic & $6(18 \%)$ \\
Portal hypertension & $1(3 \%)$ \\
Associated with lung disease and/or hypoxemia (group 3) & $16(47 \%)$ \\
Chronic obstructive pulmonary disease & $8(23 \%)$ \\
Interstitial lung disease & $3(9 \%)$ \\
Combined pulmonary fibrosis and emphysema & $3(9 \%)$ \\
Other & $2(6 \%)$ \\
Thromboembolic obstruction (group 4) & $9(26 \%)$ \\
Miscellaneous (group 5) & $2(6 \%)$ \\
\hline
\end{tabular}

Data expressed are absolute values (percent of total).

$116 \mathrm{~m}$, with a mean desaturation of $12 \pm 7 \%$ at pulse oximetry, despite nasal oxygen during the test $(4.2 \pm 3.7 \mathrm{~L} /$ min of oxygen). The diffusion capacity of the lung for carbon monoxide was markedly decreased (49 $\pm 30 \%)$, whereas the mean value of total lung capacity was $89 \pm$ $16 \%$ of predicted, and forced expiratory volume in one second/forced vital capacity was $65 \pm 11 \%$ (table 1 ).

Mean mPAP (at rest in supine position and while breathing room air) was $45.8 \pm 10.8 \mathrm{mmHg}$ (table 3 ), with mPAP higher than $35 \mathrm{mmHg}$ in $88 \%$ of patients. Mean PVR was $469 \pm 275$ dyn.s.cm ${ }^{-5}$. Mean cardiac index was $2.2 \pm 0.6 \mathrm{~L} / \mathrm{min} / \mathrm{m}^{2}$. Acute vasodilatator response tested with inhaled nitric oxide was present in none.

\section{Right-to-left shunting}

According to inclusion criteria, hypoxemia was present in all patients, with a mean $\mathrm{PaO}_{2}$ of $6.8 \pm 1.3 \mathrm{kPa}(4.5-10.0)$ in room air in supine position, and $6.8 \pm 1.4 \mathrm{kPa}(4.9-$ 10.2 ) in upright position. True RL shunting was present in all patients, with a mean Qs/Qt of $10.2 \pm 4.2 \%$. $\mathrm{AaPO}_{2}$ while breathing $100 \%$ oxygen was $32.5 \pm 12.4 \mathrm{kPa}(17.3-$ $62.5)$ in supine position, and $27.5 \pm 14.4 \mathrm{kPa}(4.5-75.5)$ in upright position.

Table 3: Hemodynamic characteristics at the time of diagnosis of pulmonary hypertension.

\begin{tabular}{lc}
\hline Hemodynamic parameters & mean \pm SD (range) \\
\hline RAP, $\mathrm{mmHg}$ & $8 \pm 4(2-16)$ \\
$\mathrm{mPAP}, \mathrm{mmHg}$ & $46 \pm 11(30-68)$ \\
$\mathrm{PAWP}, \mathrm{mmHg}$ & $8 \pm 3(2-14)$ \\
Cardiac index, $\mathrm{L} / \mathrm{min} / \mathrm{m}^{2}$ & $2.2 \pm 0.6(\mathrm{I}-3.4)$ \\
$\mathrm{SvO} 2, \%$ & $55.8 \pm 8.5(4 \mathrm{I}-72)$ \\
PVR, dyn.s.cm-5 & $469 \pm 275(142-1183)$ \\
PVRI, dyn.s.cm-5/m² & $819 \pm 446(262-2082)$
\end{tabular}

PAWP = pulmonary arterial wedge pressure; $\mathrm{mPAP}=$ mean pulmonary arterial pressure; $R A P=$ right atrial pressure; $P V R=$ pulmonary vascular resistance; $P V R I=$ pulmonary vascular resistance index; $\mathrm{SvO} 2$ = venous oxygen saturation.
The value of $\mathrm{AaPO}_{2}$ was not significantly different between etiologic groups of precapillary PH (KruskalWallis analysis, $\mathrm{p}>0.05$ ) (figure 2), although $\mathrm{PaO}_{2}$ differed significantly between etiologic groups of $\mathrm{PH}$ ( $\mathrm{p}<$ $0.05)$, with higher $\mathrm{PaO}_{2}$ at room air in patients with $\mathrm{PH}$ associated with pulmonary disease (etiologic groups 3 and 5) than in patients with chronic thromboembolic $\mathrm{PH}$ (group 4) $(7.3 \pm 1.3$ versus $6.0 \pm 0.8 \mathrm{kPa}$; $\mathrm{p}<0.05$ by Bonferroni's multiple comparison test). As expected, linear regression analysis showed that $\mathrm{AaPO}_{2}$ significantly correlated with Qs/Qt $(\mathrm{r}=0.495 ; \mathrm{p}<0.05)$; however, no significant correlation was observed between $\mathrm{AaPO}_{2}$ (or Qs/Qt) and hemodynamic parameters or carbon monoxide diffusion capacity.

None of the patients had alveolar consolidation, dilatation of pulmonary vessels, or any other lung abnormality on chest CT that could have resulted in a RL shunting.

Transthoracic contrast echocardiography showed early or late positive contrast in only $6 / 34$ patients $(18 \%)$, including 4 patients $(12 \%)$ with early contrast appearance demonstrating intracardiac RL shunting (3 patients with patent foramen ovale, and one patient with atrial septum defect), and 2 patients (6\%) with delayed contrast appearance indicating presence of intrapulmonary RL shunting. Patients with positive contrast echocardiography included 2 patients with idiopathic $\mathrm{PAH}, 3$ patients with $\mathrm{PH}$ associated with chronic obstructive pulmonary disease, and 1 patient with chronic thromboembolic disease. These 6 patients were followed for a mean of 27 months. In 2 patients, PH worsened despite therapy (epoprostenol and sildenafil; bosentan and sildenafil), AaPO2 remained elevated, and contrast echocardiography was unchanged; in three patients treated with epoprostenol and sildenafil, epoprostenol, and diuretics alone, $\mathrm{PH}$ was improved or stable, AaPO2 decreased to $10-17 \mathrm{mmHg}$, and follow-up contrast echocardiography performed in one patient with patent foramen ovale remained positive. One patient died one month after initial evaluation. Percutaneous occlusion of intracardiac RL shunting was not performed.

Clinical characteristics, pulmonary function tests, blood gas analysis at room air, echocardiography, chest imaging, and hemodynamic data were similar whatever the result of contrast echocardiography (data not shown); $\mathrm{AaPO}_{2}$ tended to be higher in patients with positive than in those with negative contrast echocardiography, although the difference was not statistically significant $(38.3 \pm 15.7 \mathrm{kPa}$ versus $31.3 \pm 11.2 \mathrm{kPa}$, respectively, Mann-Whitney U test, $\mathrm{p}=0.27)$.

\section{Discussion}

Here, we showed that, when present, true RL shunting is related to intracardiac shunt in only a minority of 
A

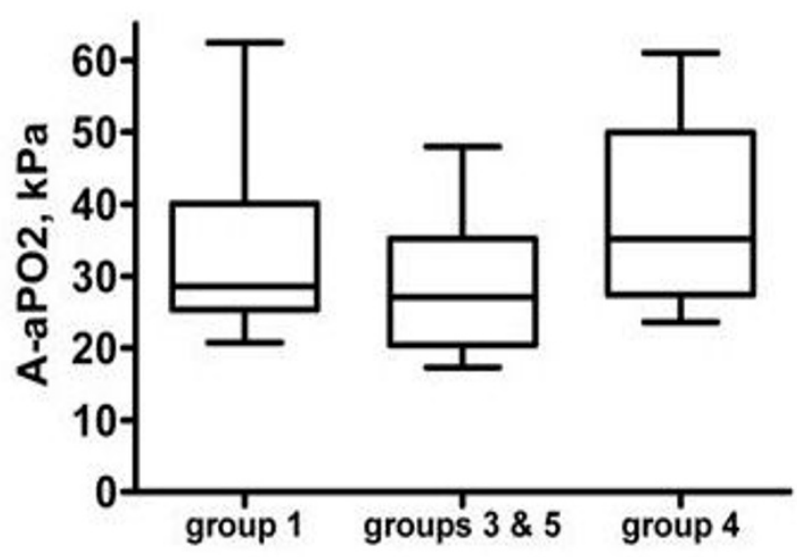

B

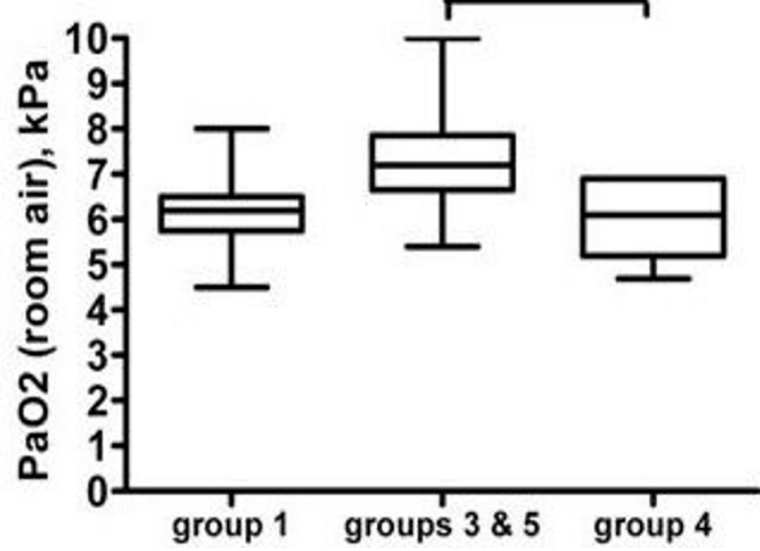

Figure 2

A, Measurement of AaPO2 while breathing $100 \%$ oxygen according to the etiologic groups of patients (difference between groups was not significant by oneway analysis of variance). $\mathrm{B}, \mathrm{PaO}_{2}$ on room air according to the etiologic groups (difference between groups was significant by Kruskal Wallis analysis, with $p<0.05$; twoby-two post-hoc analysis was significant between groups 3 and 5 , and group 4 by Bonferroni's multiple comparison test, $p<0.05)$. Group I, pulmonary arterial hypertension; group 3 , pulmonary hypertension associated with pulmonary diseases; group 4, chronic thromboembolic pulmonary hypertension; group 5, miscellaneous.

patients. Hence, intracardiac RL shunting (through reopening of a patent foramen ovale or atrial septal defect) was present in only $12 \%$ of the patients, despite a shunt frac- tion higher than physiological values (5\%) and elevated $\mathrm{AaPO}_{2}$ in all patients. This frequency is comparable to that found in the general population $[18,19]$, and in previous studies in PAH (18\%) [5] or in precapillary PH $(26 \%)$ [20]. Contrast echocardiography was performed by experienced operators involved in our previous studies on RL shunting $[15,21]$. Although transesophageal echocardiography was not performed, it is unlikely that important intracardiac shunt may have been missed by transthoracic contrast echocardiography, which has excellent sensitivity when the second harmonic mode is used $[22,23]$. Thus, we consider that RL shunting and elevated $\mathrm{AaPO}_{2}$ were not explained by intracardiac shunt in most patients.

Our findings are relevant for the clinical management of patients with precapillary $\mathrm{PH}$, whatever the etiologic group. Because hypoxemia is a potent pulmonary vasoconstrictor, and can contribute to the progression of $\mathrm{PH}$, it is recommended to maintain oxygen saturation at > $90 \%$ at all times [24]. However, hypoxemia related to RL shunting is poorly improved by supplemental oxygen therapy. Therefore, maintaining the adequacy of oxygenation, as recommended by clinical practice guidelines [24], may be difficult in patients with PH and true RL shunting. In addition, our results challenge the clinical utility of contrast echocardiography in patients with hypoxemia related to precapillary $\mathrm{PH}$.

Our study included patients with most categories of the etiologic spectrum of precapillary $\mathrm{PH}$, with no marked differences, thus showing that our findings are not restricted to any etiologic subgroup. Since the frequency and severity of RL shunting did not significantly differ between etiologic groups, and because no known cause of shunting other than PH was present, we consider that RL shunting was more likely related to precapillary $\mathrm{PH}$ than to the associated disease when present. It cannot be excluded that ventilation/perfusion mismatch participated to hypoxemia. Since Qs/Qt was greater than $5 \%$, and $\mathrm{AaPO}_{2}$ did not correlate with cardiac output, it is unlikely that increased $\mathrm{AaPO}_{2}$ was due to low cardiac output. Interestingly, RL shunting (with increased $\mathrm{AaPO}_{2}$ and a median of Qs/Qt of 19\%) was previously reported in 8 patients with severe $\mathrm{PH}$ associated with chronic obstructive pulmonary disease (with mPAP higher than $40 \mathrm{mmHg}$, "disproportionate" to the lung disease), with no evidence of intracardiac shunting at contrast echocardiography [25]. PH was moderate or severe in $88 \%$ of our cases. Whether treatment of $\mathrm{PH}$ affects RL shunting and hypoxemia remains to be determined, however some improvement of $\mathrm{AaPO}_{2}$ was observed with treatment of $\mathrm{PH}$ in few patients.

The pathophysiology of RL shunting and increased $\mathrm{AaPO}_{2}$ in our patients remains largely unknown. RL shunting was higher than physiological shunting, which represents less than $5 \%$ of cardiac output [26]. Transthoracic contrast 
echocardiography reportedly has excellent sensitivity for the detection of intrapulmonary shunt [27]. Experimental studies in normal humans and dogs have shown increased RL shunting at exertion demonstrated by elevated $\mathrm{AaPO}_{2}$, positive transthoracic contrast echocardiography, and isotope-labeled microspheres, in proportion to the increase of cardiac output [28-30], especially under hypoxic conditions [31], although with unclear consequences on $\mathrm{PaO}_{2}$. Studies in infants [32] and adults [33] have demonstrated intrapulmonary arteriovenous shunts, with up to $200 \mu \mathrm{m}$ in diameter. Large-diameter $(>25 \mu \mathrm{m})$ intrapulmonary arteriovenous pathways may be recruited with physiological exercise [30], thereby limiting the rise in PAP despite cardiac output increase [34]. In patients with $\mathrm{PAH}$, dilated and distorted capillary circulation were assumed to reflect collateral flow around obliterated pulmonary arterial segments [35]. Intrapulmonary shunting in PH may be regulated by pulmonary vascular pressure and flow [29], and may take place at the capillary level, the diameter of which may be higher than normal (7-11 $\mu \mathrm{m}$ ) but small enough to prevent the transit of microbubbles $(60-90 \mu \mathrm{m})$. RL shunting may further increase at exercise in patients with PH [36]. Thus, RL shunting in patients with $\mathrm{PH}$ might represent shunting through intrapulmonary arteriovenous pathways recruited with increase in microvascular pressure, similar to mechanisms seen during physiological exercise $[30,31]$ or hepatopulmonary syndrome [37]. Alternatively, it might be due to increase in complex anatomic anastomosis of bronchial and/or pleural circulation with the pulmonary circulation, as suggested in $\mathrm{PH}$ [38] and especially chronic thromboembolic PH [39].

Our study had limitations, including its retrospective design, and heterogeneity of causes of $\mathrm{PH}$ with potential selection bias. Although patients with various causes of precapillary $\mathrm{PH}$ were included, the distribution of causes of PH was similar in patients with or without RL shunting within the overall population of patients with $\mathrm{PH}$ in our center, and we consider that similar results would have been obtained had the patient population been restricted to PAH. We could not determine whether occurrence of RL shunting was related to more severe hemodynamic parameters, although RL shunting was observed mostly in patients with moderate to severe $\mathrm{PH}$. The effect of exercise on RL shunting was not evaluated. Contrast echocardiography was not performed in normoxic patients.

\section{Conclusion}

RL shunting was not related to reopening of patent foramen ovale in most patients with precapillary $\mathrm{PH}$ and hypoxemia related to RL shunting, as opposed to classical concepts. Our findings need confirmation by prospective systematic evaluation of hypoxemia, shunt fraction, $\mathrm{AaPO}_{2}$, and transthoracic and/or transesophageal echocardiography in consecutive patients with precapillary PH. Physiological studies are strongly needed to determine the mechanism of RL shunting and hopefully to contribute to better management of patients with $\mathrm{PH}$ and hypoxemia.

\section{Competing interests}

The authors declare that they have no competing interests.

\section{Authors' contributions}

JFV and VC performed the analysis and wrote the article. GD analysed echocardiography data. CK, ASB, BM, and JFM analysed clinical data. JYB and JCG performed the pulmonary function tests. JFC designed the study and contributed to the analysis of data and writing of the manuscript. All authors have read and approved the final manuscript.

\section{Acknowledgements}

We thank Pr G. Finet and Dr G. Rioufol (Lyon, France) who performed the right heart catheterization, Drs M. Barthelet, S. Thivolet, and C. Bergerot (Lyon) who performed the echocardiography, Dr M. Bertocchi (Lyon) who contributed to clinical care of the patients, and Dr A. Dib (Lyon) who reviewed medical charts.

Support from: «Hospices Civils de Lyon - PHRC régional 2005 maladies rares».

\section{References}

I. Simonneau G, Galie N, Rubin LJ, Langleben D, Seeger W, Domenighetti G, Gibbs S, Lebrec D, Speich R, Beghetti M, et al.: Clinical classification of pulmonary hypertension. J Am Coll Cardiol 2004, 43:5S-12S.

2. McLaughlin VV, McGoon MD: Pulmonary arterial hypertension. Circulation 2006, I I 4: |4 I7-3I.

3. Rich S, Dantzker D, Ayres S, Bergofsky E, Brundage B, Detre K, Fishman A, Goldring R, Groves B, Koerner S, et al:: Primary pulmonary hypertension: a national prospective study. Ann Int Med 1987, 1 07:216-23.

4. Hoeper MM, Pletz MW, Golpon H, Welte T: Prognostic value of blood gas analyses in patients with idiopathic pulmonary arterial hypertension. Eur Respir J 2007, 29:944-50.

5. Paciocco G, Martinez FJ, Bossone E, Pielsticker E, Gillespie B, Rubenfire $M$ : Oxygen desaturation on the six-minute walk test and mortality in untreated primary pulmonary hypertension. Eur Respir J 200I, I 7:647-52.

6. Minai OA, Pandya CM, Golish JA, Avecillas JF, McCarthy K, Marlow S, Arroliga AC: Predictors of nocturnal oxygen desaturation in pulmonary arterial hypertension. Chest 2007, I 3 I: I09-I7.

7. Melot C, Naeije R, Mols P, Vandenbossche JL, Denolin H: Effects of nifedipine on ventilation/perfusion matching in primary pulmonary hypertension. Chest 1983, 83:203-7.

8. Kapitan KS, Buchbinder M, Wagner PD, Moser KM: Mechanisms of hypoxemia in chronic thromboembolic pulmonary hypertension. Am Rev Respir Dis 1989, 139: | |49-54.

9. Dantzker DR, Bower JS: Mechanisms of gas exchange abnormality in patients with chronic obliterative pulmonary vascular disease. J Clin Invest 1979, 64:1050-5.

10. Chen WJ, Chen JJ, Lin SC, Hwang JJ, Lien WP: Detection of cardiovascular shunts by transesophageal echocardiography in patients with pulmonary hypertension of unexplained cause. Chest 1995, 107:8-13.

II. McGoon M, Gutterman D, Steen V, Barst R, McCrory DC, Fortin TA, Loyd JE: Screening, early detection, and diagnosis of pulmonary arterial hypertension: ACCP evidence-based clinical practice guidelines. Chest 2004, I 26: I4S-34S. 
12. West JB: State of the art: ventilation-perfusion relationships. Am Rev Respir Dis 1977, I I 6:919-43.

13. Chiang ST: A nomogram for venous shunt (Qs-Qt) calculation. Thorax 1968, 23:563-5.

14. Quanjer PH, Tammeling GJ, Cotes JE, Pedersen OF, Peslin R, Yernault JC: Lung volumes and forced ventilatory flows. Report Working Party Standardization of Lung Function Tests, European Community for Steel and Coal. Official Statement of the European Respiratory Society. Eur Respir J Suppl 1993, 16:5-40.

15. Cottin V, Plauchu H, Bayle JY, Barthelet M, Revel D, Cordier JF: Pulmonary arteriovenous malformations in patients with hereditary hemorrhagic telangiectasia. Am J Respir Crit Care Med 2004, 169:994-1000.

16. Galie N, Torbicki A, Barst R, Dartevelle P, Haworth S, Higenbottam T, Olschewski H, Peacock A, Pietra G, Rubin LJ, et al:: Guidelines on diagnosis and treatment of pulmonary arterial hypertension. The Task Force on Diagnosis and Treatment of Pulmonary Arterial Hypertension of the European Society of Cardiology. Eur Heart J 2004, 25:2243-78.

17. Sitbon O, Humbert M, Jais X, loos V, Hamid AM, Provencher S, Garcia G, Parent F, Herve P, Simonneau G: Long-term response to calcium channel blockers in idiopathic pulmonary arterial hypertension. Circulation 2005, I I I:3 I 05- II.

18. Hara H, Virmani R, Ladich E, Mackey-Bojack S, Titus J, Reisman M, Gray W, Nakamura M, Mooney M, Poulose A, et al.: Patent foramen ovale: current pathology, pathophysiology, and clinical status. J Am Coll Cardiol 2005, 46:1768-76.

19. Lynch JJ, Schuchard GH, Gross CM, Wann LS: Prevalence of rightto-left atrial shunting in a healthy population: detection by Valsalva maneuver contrast echocardiography. Am J Cardiol 1984, 53:| 1478-80.

20. Nootens MT, Berarducci LA, Kaufmann E, Devries S, Rich S: The prevalence and significance of a patent foramen ovale in pulmonary hypertension. Chest 1993, 104:1673-5.

21. Mas JL, Arquizan C, Lamy C, Zuber M, Cabanes L, Derumeaux G, Coste ]: Recurrent cerebrovascular events associated with patent foramen ovale, atrial septal aneurysm, or both. N Engl J Med 200I, 345: 1740-6

22. Kuhl HP, Hoffmann R, Merx MW, Franke A, Klotzsch C, Lepper W, Reineke T, Noth J, Hanrath P: Transthoracic echocardiography using second harmonic imaging: diagnostic alternative to transesophageal echocardiography for the detection of atria right to left shunt in patients with cerebral embolic events. Am Coll Cardiol 1999, 34: 1823-30.

23. Van Camp G, Franken P, Melis P, Cosyns B, Schoors D, Vanoverschelde JL: Comparison of transthoracic echocardiography with second harmonic imaging with transesophageal echocardiography in the detection of right to left shunts. Am J Cardiol 2000, 86: I284-7. A9

24. Badesh DB, Abman SH, Ahearn GS, Barst RJ, McCrory DC, Simonneau G, McLaughlin VV: Medical therapy for pulmonary arterial hypertension: ACCP evidence-based clinical practice guidelines. Chest 2004, 126:35s-62s.

25. Chaouat A, Bugnet AS, Kadaoui N, Schott R, Enache I, Ducolone A, Ehrhart M, Kessler R, Weitzenblum E: Severe pulmonary hypertension and chronic obstructive pulmonary disease. Am J Respir Crit Care Med 2005, I 72:189-94.

26. Comroe JH Jr, Foster RE, DuBois AB, Briscoe WA, Carlsen E: The Lung 2nd edition. Chicago: Year Book Medical Publishers; 1962.

27. Lee WL, Graham AF, Pugash RA, Hutchison SJ, Grande P, Hyland RH, Faughnan ME: Contrast echocardiography remains positive after treatment of pulmonary arteriovenous malformations. Chest 2003, I 23:35I-8.

28. Stickland MK, Welsh RC, Haykowsky MJ, Petersen SR, Anderson WD, Taylor DA, Bouffard M, Jones RL: Intra-pulmonary shunt and pulmonary gas exchange during exercise in humans. Physiol 2004, 56 I:321-9.

29. Eldridge MW, Dempsey JA, Haverkamp HC, Lovering AT, Hokanson S: Exercise-induced intrapulmonary arteriovenous shunting in healthy humans. J Appl Physiol 2004, 97:797-805.

30. Stickland MK, Lovering AT, Eldridge MW: Exercise-induced arteriovenous intrapulmonary shunting in dogs. Am J Respir Crit Care Med 2007, 176:300-5.

31. Lovering AT, Stickland MK, Eldridge MW: Intrapulmonary shunt during normoxic and hypoxic exercise in healthy humans. Adv Exp Med Biol 2006, 588:31-45.
32. Wilkinson MJ, Fagan DG: Postmortem demonstration of intrapulmonary arteriovenous shunting. Arch Dis Child 1990, 65:435-7.

33. Tobin CE: Arteriovenous shunts in the peripheral pulmonary circulation in the human lung. Thorax 1966, 21:197-204.

34. Chemla D, Castelain V, Herve P, Lecarpentier Y, Brimioulle S: Haemodynamic evaluation of pulmonary hypertension. Eur Respir J 2002, 20: | 3| 4-31.

35. Reeves JT, Noonan JA: Microarteriographic studies of primary pulmonary hypertension. A quantitative approach in two patients. Arch Pathol 1973, 95:50-5.

36. Sun XG, Hansen JE, Oudiz RJ, Wasserman K: Gas exchange detection of exercise-induced right-to-left shunt in patients with primary pulmonary hypertension. Circulation 2002, 105:54-60.

37. Rodriguez-Roisin R, Krowka MJ: Hepatopulmonary syndrome a liver-induced lung vascular disorder. N Engl J Med 2008, 358:2378-87.

38. Romano JT, Tomaselli S, Gualtieri G, Zoia MC, Fanfulla F, Berrayah L, Cerveri I: Respiratory function in precapillary pulmonary hypertension. Monaldi Arch Chest Dis 1993, 48:201.

39. Remy-Jardin M, Duhamel A, Deken V, Bouaziz N, Dumont P, Remy J: Systemic collateral supply in patients with chronic thromboembolic and primary pulmonary hypertension: assessment with multi-detector row helical CT angiography. Radiology 2005, 235:274-8I.

\section{Pre-publication history}

The pre-publication history for this paper can be accessed here:

http://www.biomedcentral.com/1471-2261/9/15/prepub

Publish with BioMed Central and every scientist can read your work free of charge

"BioMed Central will be the most significant development for disseminating the results of biomedical research in our lifetime. "

Sir Paul Nurse, Cancer Research UK

Your research papers will be:

- available free of charge to the entire biomedical community

- peer reviewed and published immediately upon acceptance

- cited in PubMed and archived on PubMed Central

- yours - you keep the copyright

Submit your manuscript here:

http://www.biomedcentral.com/info/publishing_adv.asp

BioMedcentral 